\title{
Preparation of Si/C composite nanofibers by electrospinning method using as the lithium-ion battery anode
}

\author{
Yueqin Ban ${ }^{1, a}$, Weiquan Shao ${ }^{1,2, b}$, Shaou Chen ${ }^{1,2, b}$, Lizhu He ${ }^{2, b}$, Hailing Zhu ${ }^{3, c}$, \\ Jiajia Feng ${ }^{2, b}$, Xiaojie $\mathrm{Guo}^{2, \mathrm{~b}}$, Yanqiang $\mathrm{Li}^{2, \mathrm{~b}}$, Haifeng Zhao ${ }^{2, \mathrm{~b}}$ and Yingnan \\ Zhang ${ }^{2, b}$ \\ ${ }^{1}$ College of physics, Qingdao University, Qingdao 266071, China \\ ${ }^{2}$ Key Laboratory of Photonics Materials and Technology in Universities of Shandong, Qingdao \\ University, Qingdao 266071, China \\ ${ }^{3}$ Department of Physics and Optoelectronic Engineering, Weifang University, Weifang 261061, \\ China

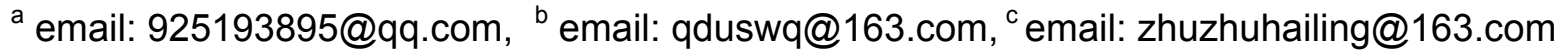

Keywords: Lithium-ion battery anode; Si nanoparticles; Carbon coating; Electrospinning.

\begin{abstract}
Si was a promising anode material for next-generation LIBs due to its extremely large capacity of $4200 \mathrm{mAh} / \mathrm{g}$ ( $\mathrm{Li}_{4.4} \mathrm{Si}$ phase). However, during repeated lithium insertion/extraction processes, the accompanied huge volume change (400\%) induced the structural failure of the active material and resulted in rapid capacity fading. To overcome this problem, $\mathrm{Si} / \mathrm{C}$ composite nanofibers with porous structure were prepared through a facile electrospinning method. The inclusion of carbon not only worked as a stable electric conductive pathway but also buffered the volume expansion of silicon during the process of charging and discharging. The first discharge capacity of the composite nanofiber (26wt.\% and 50wt.\% Si) electrode reaches $1840 \mathrm{mAh} / \mathrm{g}, 2042 \mathrm{mAh} / \mathrm{g}$, and it delivered a charge capacity of $1461 \mathrm{mAh} / \mathrm{g}, 1644 \mathrm{mAh} / \mathrm{g}$ at the first cycle, corresponding to an initial coulombic efficiency of $79 \%$ and $80 \%$. In contrast, the cell with the pure Si nanoparticle exhibited an initial discharge/charge capacity of 18 and $13 \mathrm{mAh} / \mathrm{g}$, respectively, which was much lower than the composite nanofiber electrode.
\end{abstract}

\section{Introduction}

Lithium-ion batteries (LIBs) have been widely used in many types of portable devices due to their high specific energy, high battery voltage, and long cycle life. As the conventional anode materials, the commercialized carbon has a lower theoretical specific of $372 \mathrm{mAh} / \mathrm{g}[1,2]$, which cannot satisfy the high specific capacity requirement for the future use. Therefore, alternative high capacity anode materials are strongly required. Silicon has high theoretical specific capacity $(4200 \mathrm{mAh} / \mathrm{g})$ [3] and low working potential, which can be used as the lithium-ion battery anode materials in the future.

However, in the process of charging and discharging, Si has large volume changes (400\%) [3].This huge volume change gives rise to the collapse of electrodes and insulation of active material, eventually resulting in rapid capacity fading and poor cycle performance. How to improve specific capacity of silicon and make the cycle performance of silicon-based anode materials better become the research focus. Many Si-based materials with different morphologies such as nanoparticles, nanofibers, nanotubes, nanorods and nanowires [4] were prepared. Si-based nanofibers can not only provide higher electric conductivity, but also can effectively slow down the huge volume changes [5, 6]. In this paper, the $\mathrm{Si} / \mathrm{C}$ composite nanofibers were prepared by the electrospinning method. Different mass Si was dispersed into the carbon nanofibers, which possessed good elasticity to maintain the structure integrity [7] and stable electrically-conductive networks. 


\section{Material and Methods.}

Si powder $(0.20 \mathrm{~g}, 0.40 \mathrm{~g}, 100 \mathrm{~nm}$ in diameter, Nanostructured \& Amorphous Materials, Inc) and polyvinylpyrrolidone (1.0g, PVP K90, Pfaltz \& Bauer Inc) were dispersed in ethanol (10ml) with magnetic stirring for $12 \mathrm{~h}$ and kept in the ultrasonic bath for 20min. Electrospinning was carried out to form $\mathrm{Si} / \mathrm{C}$ nanofibers with a $0.4 \mathrm{~mL} / \mathrm{h}$ flow rate, $17 \mathrm{~cm}$ needle-to-collector distance, and $22 \mathrm{kV}$ voltage. Electrospun $\mathrm{Si} / \mathrm{C}$ nanofibers were first stabilized in air at $250{ }^{\circ} \mathrm{C}$ for $30 \mathrm{~min}$ (heating rate was $5{ }^{\circ} \mathrm{C}$ $/ \mathrm{min}$ ) and then carbonized at $650{ }^{\circ} \mathrm{C}$ for $7 \mathrm{~h}$ in argon (heating rate was $2{ }^{\circ} \mathrm{C} / \mathrm{min}$ ) to form $\mathrm{Si} / \mathrm{C}$ nanofibers. For comparison, Si without the carbon coating were also prepared. The crystal structures of the treated powders were analyzed by X-ray diffractometry (XD3). The morphologies of the particles were characterized by scanning electron microscopy (SEM, FEI, XL 30S-FEG).

The electrode was prepared by mixing $80 \mathrm{wt} . \%$ active material with $10 \mathrm{wt} . \%$ acetylene black and $10 \mathrm{wt} . \%$ polyvinylidene difluoride (PVDF) binder, coating the mixture on an copper foil, and then cutting the sheet into pieces with $1 \mathrm{~cm} \times 1 \mathrm{~cm}$, which was dried at $120{ }^{\circ} \mathrm{C}$ for $12 \mathrm{~h}$ to achieve the anode. The CR2032 coin cell was assembled in an Ar-filled Mikrouna glove box by using the prepared electrode as anode, lithium film as the counter electrode, Celgard 2400 as separator and 1MLiPF6 in EC:DMC (1:2 in volume) as electrolyte. The electrochemical performance was investigated by carrying out galvanostatic charge-discharge experiments between cut-off potentials of 0.02 and $2.0 \mathrm{~V}$ at constant current densities of $42 \mathrm{~mA} / \mathrm{g}$ using Land cell test system (Land CT2001A, China).

\section{Results and Discussion}

Figure. 1 showed the XRD patterns of the pure $\mathrm{Si}$ powder, $\mathrm{Si} / \mathrm{C}$ composites with $26 \mathrm{wt} . \%$ and 50wt.\%. The pure Si (Fig.1a) presented well-defined peaks at $2 \theta$ of $28.4^{\circ}, 47.4^{\circ}, 56.2^{\circ}, 69.2^{\circ}$, $76.5^{\circ}$ and $88.1^{\circ}$, which were assigned to the (111), (220), (311), (400), (331) and (422) planes of crystalized Si, respectively (JCPDSNo.27-1402) [8]. After sintering at $650{ }^{\circ} \mathrm{C}$ in argon, the structure of the Si powder coated by carbon unchanged since no apparent changes could be observed for all XRD diffraction peaks (Fig. $1 b$ and $c$ ). The carbon was not detected because of its amorphous structure.

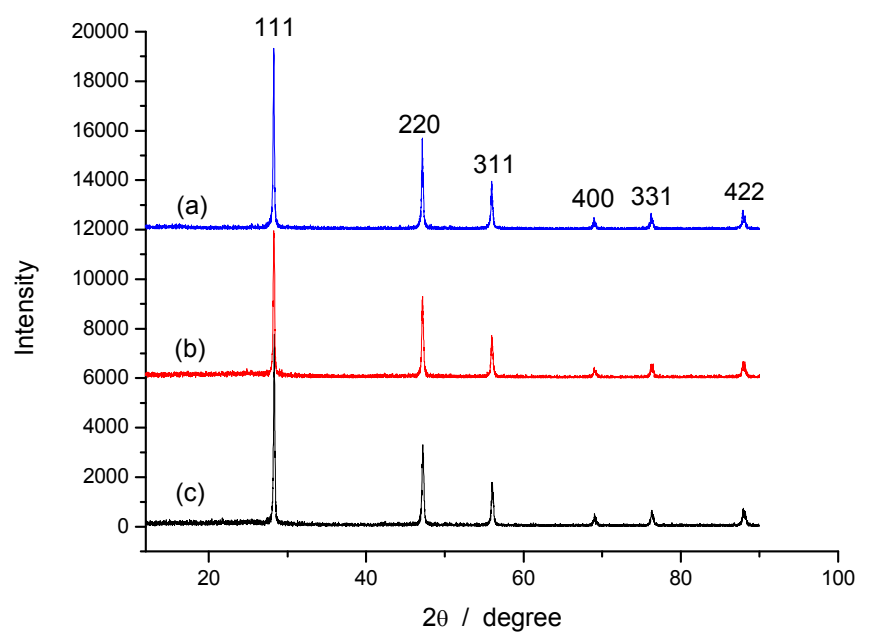

Figure 1: X-ray diffraction patterns of (a) Si nanoparticles, (b) $\mathrm{Si} / \mathrm{C}$ composite with 26 wt.\% Si (c) Si/C composite with 50wt.\% Si

Figure. 2a showed the plane-view SEM images of the Si/C nanofibers (26wt.\% Si) before sintering. From the surface direction, the sample exhibited an interconnected network structure composed of nanofibers with diameters of $1 \mu \mathrm{m}$, and the fiber surface appeared uneven due to the presence of $\mathrm{Si}$ nanoparticles. This network structure was good for the cycling stability of Si because it had excellent structural buffering effect to absorb the mechanical stress induced by the volume changes of $\mathrm{Si}[3,9]$. 
Fig. $2 \mathrm{~b}$ showed the $\mathrm{Si} / \mathrm{C}$ composite (26wt.\% Si) sample with aggregated porous structure, the porous structure could accommodate the Si volume expansion in the process of charging and discharging process. As shown in Fig. 2c for the $\mathrm{Si} / \mathrm{C}$ composite (50wt.\% $\mathrm{Si}$ ) sample, some $\mathrm{Si}$ aggregated into bigger particles with the size of 2-3 um due to the Si content increasing. At the same time, carbon flakes in size around 1 um appeared in the composites, which was helpful for the conductivity improvement.
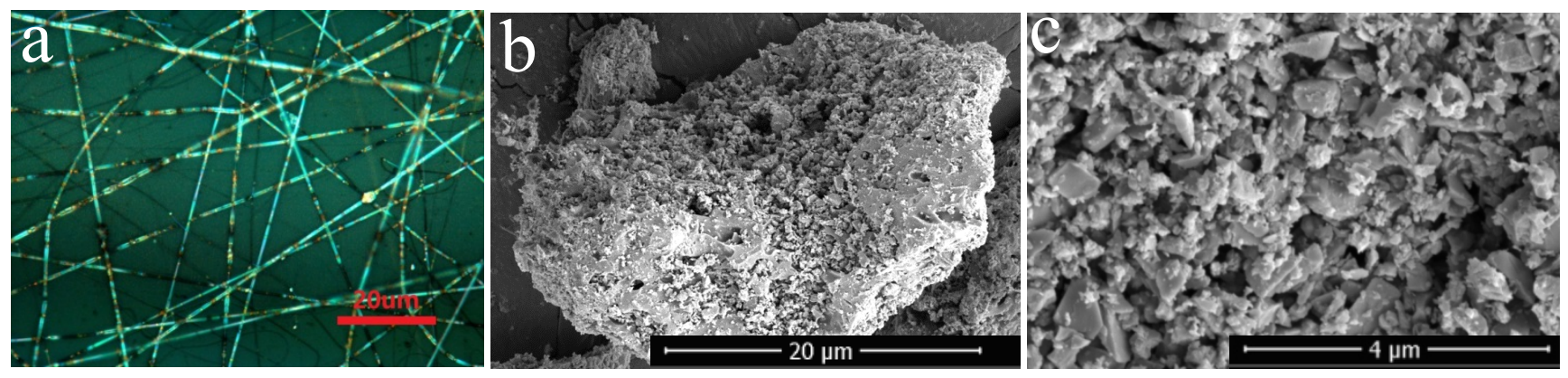

Figure 2: Images of the Si/C composite with 26wt.\% Si (before sintering (a), after sintering (b) )and 50wt.\% Si sample sintered(c)
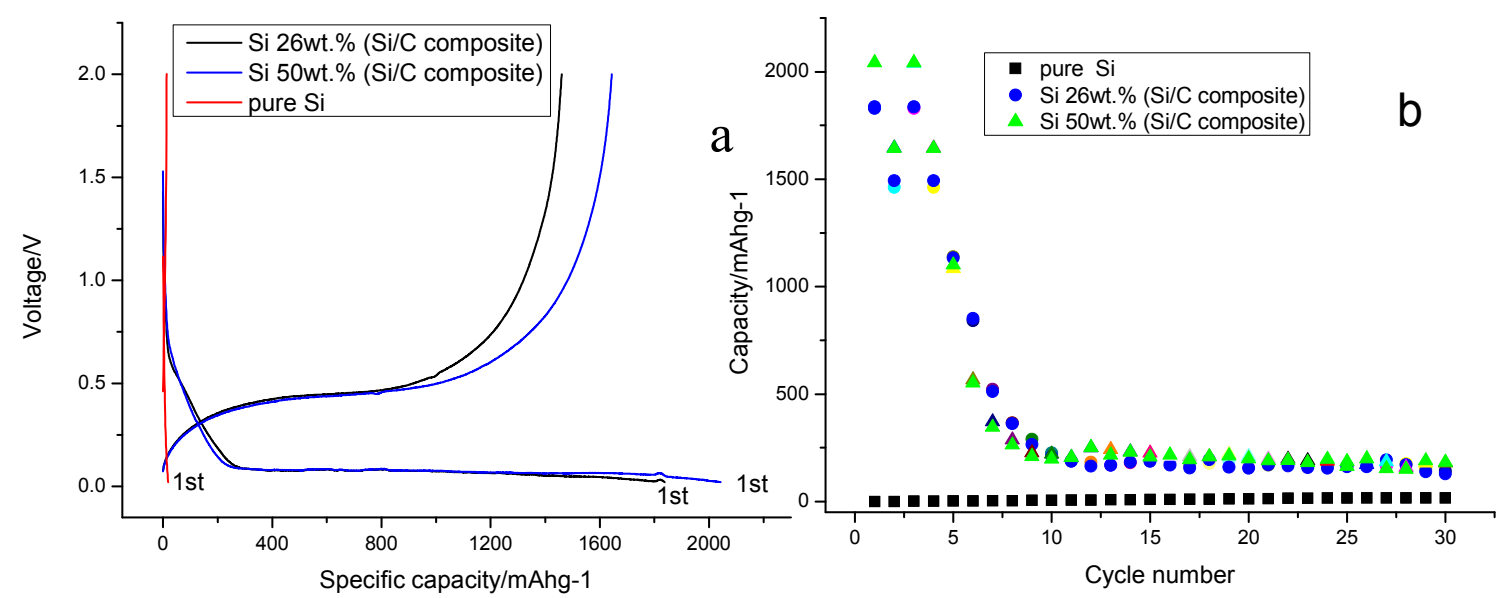

Figure 3: Voltage profiles (a) and Cycling performance (b) for the pristine $\mathrm{Si}$ and $\mathrm{Si} / \mathrm{C}$ composite at $42 \mathrm{~mA} / \mathrm{g}$

Figure.3a showed the typical voltage profiles of the pure $\mathrm{Si}$ and the $\mathrm{Si} / \mathrm{C}(26 \mathrm{wt} . \%$ and $50 \mathrm{wt} . \% \mathrm{Si})$ composite nanofiber electrode cycled between 0.02 and $2.0 \mathrm{~V}$ at $42 \mathrm{~mA} / \mathrm{g}$, respectively. The first discharge capacity of the composite (26wt.\% and 50wt.\% Si) electrode reaches $1840 \mathrm{mAh} / \mathrm{g}$, $2042 \mathrm{mAh} / \mathrm{g}$, and it delivered a charge capacity of $1461 \mathrm{mAh} / \mathrm{g}, 1644 \mathrm{mAh} / \mathrm{g}$ at the first cycle, corresponding to an initial coulombic efficiency of $79 \%$ and $80 \%$. The low efficiency for the first charge/discharge could be mainly due to the larger surface area of the carbon-coated Si nanoparticles with porous nanofiber structure and formation of irreversible solid electrolyte interphase (SEI) layer $[5,10]$ in the first discharge process. In contrast, the cell with the pure Si nanoparticle exhibited an initial discharge/charge capacity of 18 and $13 \mathrm{mAh} / \mathrm{g}$, respectively, which was much lower than the composite electrode. The results provided clear evidence that the carbon-coated Si nanoparticles with porous nanofiber structure can enhance Li storage properties.

Figure.3b displayed the cycling performances of the $\mathrm{Si} / \mathrm{C}$ composite $(26 \mathrm{wt} . \%$ and $50 \mathrm{wt} . \% \mathrm{Si}$ ) electrodes and Si nanoparticle electrode. It could be seen that the capacity of the pure Si electrode decreased to about $17 \mathrm{mAh} / \mathrm{g}$ after 30 cycles. As shown in Fig. 3b, the Si/C anode retained the reversible discharge capacity of $183 \mathrm{mAh} / \mathrm{g}$ at the 30 th cycle. In all 30 cycles, $\mathrm{Si} / \mathrm{C}$ composite nanofibers had higher capacities and better capacity retentions than the pure Si due to the protection of Si with carbon. 

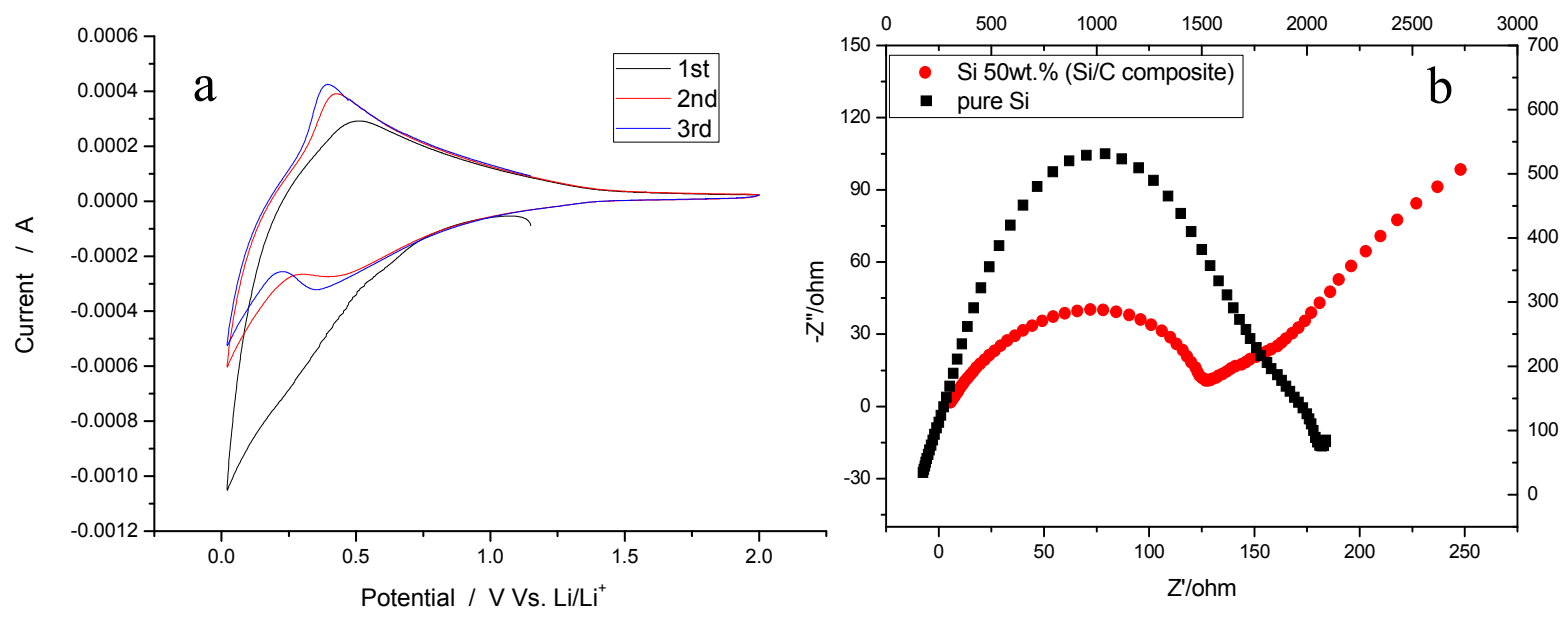

Figure 4: (a)Cyclic voltammograms of the Si/C composite (26wt.\%) nanofiber electrode between 0.02 and $2.0 \mathrm{~V}\left(\mathrm{vs} . \mathrm{Li} / \mathrm{Li}^{+}\right.$) at room temperature and the impedance spectra;

(b) The impedance spectra of the $\mathrm{Si} / \mathrm{C}$ composite (50wt.\% Si) nanofiber electrode.

Figure.4a showed the $\mathrm{C}-\mathrm{V}$ profiles of the $\mathrm{Si} / \mathrm{C}$ composite (50wt. \% $\mathrm{Si}$ ) electrode measured between 0.02 and $2.0 \mathrm{~V}$ (versus $\mathrm{Li} / \mathrm{Li}+$ ) at a scanning rate of $0.1 \mathrm{mV} / \mathrm{s}$ for the first 3 cycles. For the composite nanofibers, there is a broad cathodic peak between 0.25 and $0.70 \mathrm{~V}$ at the first cycle, which was resulted from the decomposition of the electrolyte and the formation of SEI film [1, 10]. It could be found that the cathodic peak of the third cycle became smaller and narrower compared with that of the first and the second cycle, indicating that the SEI formation is reduced. For the third cycle, the anodic peak at $0.39 \mathrm{~V}$ corresponded to the alloying and de-alloying process of $\mathrm{Li}-\mathrm{Si}$ alloys, which became clearer than those in the first cycle. The anodic current peaks exhibited an enhanced intensity from the first cycle to the third cycle, which could be attributed mainly to the gradual formation of the complete amorphization that depended on the migration rate of Li-ions into the silicon host [10].

Fig. $4 \mathrm{~b}$ showed the impedance spectra of the pure $\mathrm{Si}$ and the $\mathrm{Si} / \mathrm{C}$ composite nanofiber $(50 \mathrm{wt} . \% \mathrm{Si}$ ) electrode with the first cycle. The electrochemical impedance spectra consist of one depressed semicircle and a line. The semicircle at high frequency can be ascribed to the charge transfer resistance, which is related to the electrochemical reaction between the particles or between the electrode and the electrolyte. The sloping line is related to lithium-ion diffusion in the active material $[11,12]$. As shown in Fig. 4b, the charge transfer resistance of $\mathrm{Si} / \mathrm{C}$ composite nanofiber anode was $90 \Omega$ at the first cycle, whereas it increased greatly to $2070 \Omega$ for the pure Si. The improvement in the electrochemical performance for $\mathrm{Si} / \mathrm{C}$ composite could be attributed to good electrical contact between the active materials and carbon during the lithium insertion and extraction cycles.

\section{Conclusion}

$\mathrm{Si} / \mathrm{C}$ composite nanofibers with porous structure were prepared through a facile electrospinning method. The inclusion of carbon not only worked as a stable electric conductive pathway but also buffer the volume expansion of silicon during the process of charging and discharging. The first discharge capacity of the composite nanofiber (26wt.\% and 50wt.\% Si) electrode reaches $1840 \mathrm{mAh} / \mathrm{g}$, $2042 \mathrm{mAh} / \mathrm{g}$, and it delivered a charge capacity of $1461 \mathrm{mAh} / \mathrm{g}, 1644 \mathrm{mAh} / \mathrm{g}$ at the first cycle, corresponding to an initial coulombic efficiency of $79 \%$ and $80 \%$. In contrast, the cell with the pure Si nanoparticle exhibited an initial discharge/charge capacity of 18 and $13 \mathrm{mAh} / \mathrm{g}$, respectively, which was much lower than the composite nanofiber electrode. In all 30 cycles at the current of $42 \mathrm{~mA} / \mathrm{g}, \mathrm{Si} / \mathrm{C}$ composite nanofibers had higher capacities and better capacity retentions than the pure $\mathrm{Si}$ due to the protection of Si with carbon. According to the impedance spectra, the charge transfer resistance of $\mathrm{Si} / \mathrm{C}$ composite nanofiber anode was $90 \Omega$, whereas it increased greatly to $2070 \Omega$ for the pure Si. 


\section{Acknowledgements}

This work was supported by the Natural Science Foundation of Shandong Province (ZR2014EMQ005, ZR2010EQ001), the Project of Shandong Province Higher Educational Science and Technology Program (Grant No. J14LJ08, J15LA13), the Taishan Scholars Program of Shandong Province (ts20120528), China.

\section{References}

[1] Ying Li, Guanjie Xu, Yingfang Yao, Leigang Xue, Meltem Yanilmaz, Hun Lee, Xiangwu Zhang. Coaxial electrospun $\mathrm{Si} / \mathrm{C}-\mathrm{C}$ core-shell composite nanofibers as binder-free anodes for lithium-ion batteries. Solid State Ionics, vol. 158, pp.67-73, 2014.

[2] Byoung-Sun Lee, Seoung-Bum Son, Kyu-Min Park, Jong-Hyun Seo, Se-Hee Lee, In-Suk Choi, Kyu-Hwan Oh, Woong-Ryeol Yu. Fabrication of Si core/C shell nanofibers and their electrochemical performances as a lithium-ion battery anode. Journal of Power Sources, vol. 206, pp.267-273, 2012.

[3] Leigang Xue, Kun Fu, Ying Li, Guanjie Xu, Yao Lu, Shu Zhang,Ozan Toprakci, Xiangwu Zhang. $\mathrm{Si} / \mathrm{C}$ composite nanofibers with stable electric conductive network for use as durable lithium-ion battery anode. Nano Energy, vol. 2, pp.361-367,2013.

[4] Magali Gauthier, David Reyter, Driss Mazouzi. From Si wafers to cheap and efficient Si electrodes for Li-ion batteries. Journal of Power Sources, vol. 256, pp. 32-36,2014.

[5] Dingsheng Wang, Mingxia Gao, Hongge Pan, Junhua Wang, Yongfeng Liu. High performance amorphous-Si/SiOx /C composite anode materials for Li-ion batteries derived from ball-milling and in situ carbonization. Journal of Power Sources, vol. 256, pp. 190-199, 2014.

[6] Dingsheng Wang, Mingxia Gao, Hongge Pan, Yongfeng Liu, Junhua Wang, Shouquan Li, Hongwei Ge. Enhanced cycle stability of micro-sized Si/C anode material with low carbon content fabricated via spray drying and in situ carbonization. Journal of Alloys and Compounds, vol. 604, pp. 130-136, 2014.

[7] T. Cetinkaya, M.O. Guler, H. Akbulut. Enhancing electrochemical performance of silicon anodes by dispersing MWCNTs using planetary ball milling. Microelectronic Engineering, vol. 108, pp.169-176, 2013.

[8] Tugrul Cetinkaya, Mehmet Uysal, Mehmet O. Guler, Hatem Akbulut, Ahmet Alp. Improvement cycleability of core-shell silicon/copper composite electrodes for Li-ion batteries by using electroless deposition of copper on silicon powders. Powder Technology, vol. 253, pp. 63-69, 2014.

[9] Congxiang Lu, Yu Fan, Hong Li, Yi Yang. Core-shell CNT-Ni-Si nanowires as a high performance anode material for lithium ion batteries. CARBON, vol. 63, pp. 54-60, 2013.

[10] Lianyi Shao, Jie Shu, Kaiqiang Wu, Xiaoting Lin, Peng Li, Miao Shui. Low pressure preparation of spherical $\mathrm{Si} / \mathrm{C} / \mathrm{CNT} / \mathrm{C}$ anode material for lithium-ion batteries. Journal of Electroanalytical Chemistry, vol. 727, pp. 8-12, 2014.

[11] QU Chao-Qun, WANG Yu-Hui, JIANG Tao, BIE Xiao-Fei. Synthesis and Characterization of $\mathrm{Si} / \mathrm{C}$ Composite Anode by Electrostatic Spinning Method. Journal of Inorganic Materials, vol. 29, no.2, pp.197-202, 2014.

[12] Tugrul Cetinkaya, Mehmet Uysal, Mehmet O. Guler, Hatem Akbulut. Developing lithium ion battery silicon/cobalt core-shell electrodes for enhanced electrochemical properties. International journal of hydrogen energy, vol. 39, pp.21405-21413, 2014. 